\title{
Cobertura do solo e acumulação de nutrientes pelo amendoim forrageiro ${ }^{(1)}$
}

\author{
Adriano Perin ${ }^{(2)}$, José Guilherme Marinho Guerra ${ }^{(3)}$ e Marcelo Grandi Teixeira ${ }^{(3)}$ \\ Resumo - O objetivo deste trabalho foi determinar as taxas de cobertura do solo, produção de biomassa \\ e acumulação total de N, P e K da parte aérea da leguminosa herbácea perene amendoim forrageiro \\ (Arachis pintoi Krapov. \& W.C. Greg.), em diferentes densidades e espaçamentos de plantio. \\ O delineamento experimental adotado foi de blocos ao acaso, em arranjo fatorial $2 \times 4$, com quatro \\ repetições. Os tratamentos constaram de espaçamentos entre sulcos de plantio $(25$ e $50 \mathrm{~cm})$, e de den- \\ sidades de plantas (2, 4, 8 e 16 plantas/m linear). A cobertura total do solo ocorreu aos 224 dias após o \\ plantio. Foram constatadas diferenças de densidades de plantio na taxa de cobertura do solo, produção \\ de biomassa e acúmulo de nutrientes na parte aérea do amendoim forrageiro. Todavia, não foram obser- \\ vadas diferenças quando se variou o espaçamento entre sulcos. Entre as alternativas testadas, a densi- \\ dade de 8 plantas $/ \mathrm{m}$ linear no espaçamento de $50 \mathrm{~cm}$ entre sulcos de plantio foi a combinação mais \\ adequada para a plena formação da cobertura viva com amendoim forrageiro.
}

Termos para indexação: Arachis pintoi, população vegetal, espaçamento, parte aérea, teor em matéria seca.

\section{Soil coverage and nutrient accumulation by pinto peanut}

\begin{abstract}
The objective of this work was to determine the rate of soil coverage, biomass yield and total accumulation of N, P and K in the aerial biomass of the legume Arachis pintoi Krapov. \& W.C. Greg. The experimental design was a randomized block with four replicates arranged in a $2 \times 4$ factorial with two levels of row spacing ( 25 and $50 \mathrm{~cm}$ between rows) and four different planting densities $(2,4,8$ and 16 plants $/ \mathrm{m}$ ). Complete soil coverage was achieved 224 days after planting. Planting density affected the rate of soil coverage and the rate of dry matter and nutrient accumulation by the shoot tissue of the legume, but these parameters were not significantly affected by row spacing. The results suggest that the optimum planting density was 8 plants $/ \mathrm{m}$ in rows spaced $50 \mathrm{~cm}$ apart.
\end{abstract}

Index terms: Arachis pintoi, plant population, spacing, aerial parts, dry matter contents.

\section{Introdução}

Práticas de manejo e conservação, como o emprego de plantas de cobertura, são relevantes para a manutenção ou melhoria das características químicas, físicas e biológicas dos solos. A adubação verde utiliza espécies de diferentes famílias botânicas, nativas ou introduzidas, que cobrem o terreno em períodos de tempo ou durante todo ano. As leguminosas se destacam por formarem associações simbióticas com bactérias fixadoras de $\mathrm{N}_{2}, \mathrm{o}$

\footnotetext{
(1)Aceito para publicação em 25 de março de 2003.

(2)Universidade Federal de Viçosa, Dep. de Fitotecnia, Avenida P. H. Rolfs, s/n, CEP 36571-000 Viçosa, MG. E-mail: aperin@vicosa.ufv.br

(3)Embrapa-Centro Nacional de Pesquisa de Agrobiologia, Caixa Postal 74505, CEP 23890-000 Seropédica, RJ. E-mail gmguerra@cnpab.embrapa.br, grandi@cnpab.embrapa.br
}

que resulta no aporte de quantidades expressivas desse nutriente no sistema solo-planta.

Ações de pesquisa têm visado principalmente a geração de base técnico-científica para o emprego de leguminosas anuais. No entanto, há espécies herbáceas de ciclo perene, de uso forrageiro, com grande potencial de utilização como cobertura viva permanente de solo, notadamente em pomares. A cobertura viva protege o solo dos agentes climáticos, mantém ou aumenta o teor de matéria orgânica do solo, mobiliza e recicla nutrientes e favorece a atividade biológica do solo (Guerra \& Teixeira, 1997; Perin, 2001; Duda et al., 2003). Contudo, a identificação e adequação desse grupo de leguminosas nos sistemas de produção é ainda um desafio.

Além disso, as leguminosas perenes competem com espécies de ocorrência espontânea e interferem no ciclo reprodutivo das mesmas, o que reduz a 
mão-de-obra empregada no controle da vegetação espontânea (Lanini et al., 1989; Wiles et al., 1989; Sarrantonio, 1992). No cultivo de hortaliças, Kleinhenz et al. (1997) constataram que o uso das espécies centrosema (Centrosema pubescens), siratro (Macroptilium atropurpureum) e desmódio (Desmodium intortum) promoveram o controle das espécies espontâneas, não prejudicaram o desempenho das hortaliças e forneceram $\mathrm{N}$ para as culturas.

Um aspecto importante na implantação da cobertura viva são as taxas de crescimento das leguminosas perenes, inicialmente lentas, quando comparadas com leguminosas anuais (Perin et al., 2000). Desta forma, cuidados que assegurem a supressão da vegetação espontânea, até que as plantas se estabeleçam, são necessários (Perin, 2001).

Trabalhos relacionando arranjos populacionais e desempenho de leguminosas anuais evidenciaram a importância da densidade de plantio para a produção de grãos de soja (Glycine max) (Pires et al., 2000), feijão (Phaseolus vulgaris) (Horn et al., 2000), e de matéria seca de parte aérea de diversos adubos verdes (Fernandes et al., 1999; Amabile et al., 2000). Observa-se, porém, carência de informações relativas às leguminosas herbáceas perenes.

O objetivo deste trabalho foi determinar as taxas de cobertura do solo, produção de biomassa e acumulação total de $\mathrm{N}, \mathrm{P}$ e $\mathrm{K}$ da parte aérea da leguminosa herbácea perene amendoim forrageiro, em diferentes densidades e espaçamentos de plantio.

\section{Material e Métodos}

$\mathrm{O}$ experimento foi realizado na Embrapa-Centro Nacional de Pesquisa de Agrobiologia, Seropédica, RJ, num Argissolo Vermelho-Amarelo. Os resultados da análise química $(0-20 \mathrm{~cm})$ de amostras de terra no início do experimento apresentaram os seguintes valores: $\mathrm{pH}$ em $\mathrm{H}_{2} \mathrm{O}(1: 2,5), 4,1 ; \mathrm{Al}^{3+}, 0,4 \mathrm{cmol}_{\mathrm{c}} / \mathrm{dm}^{3} ; \mathrm{Ca}^{2+}, 2,1 \mathrm{cmol}_{\mathrm{c}} / \mathrm{dm}^{3}$. $\mathrm{Mg}^{2+}, 0,9 \mathrm{cmol}_{\mathrm{c}} / \mathrm{dm}^{3} ; \mathrm{K}^{+}, 34 \mathrm{mg} / \mathrm{kg}$ e $\mathrm{P}, 6 \mathrm{mg} / \mathrm{kg}$ de solo. Apesar dos baixos valores de $\mathrm{pH}$ e dos nutrientes avaliados, não se aplicou calcário e fertilizantes no solo porque o amendoim forrageiro é considerado uma espécie rústica.

O delineamento experimental adotado foi o de blocos ao acaso, com arranjo fatorial $2 \times 4$, com quatro repetições.
Os tratamentos constaram de dois espaçamentos entre sulcos de plantio $(25 \mathrm{~cm}$ e $50 \mathrm{~cm})$ e de quatro densidades de plantas (2, 4, 8 e 16 plantas/m linear), perfazendo oito arranjos populacionais (40.000 a 640.000 plantas/ha ou 4 a 64 plantas $/ \mathrm{m}^{2}$ ).

As parcelas constaram de uma área de $4 \mathrm{~m}^{2}(2 \times 2 \mathrm{~m})$. As mudas da leguminosa de ciclo perene e hábito de crescimento rasteiro do amendoim forrageiro (Arachis pintoi acesso BR-14951 seção estolonífera) foram preparadas vegetativamente tomando-se por base estacas em bandejas de poliestireno expandido com 200 células que permaneceram no viveiro por 70 dias. Em março/98 (final do período chuvoso), foram transferidas para a área experimental. Estirpes de bactérias do gênero Rhizobium, recomendadas pela Embrapa-Centro Nacional de Pesquisa de Agrobiologia, foram inoculadas nas estacas, usando-se a água como veículo. Capinas manuais foram realizadas aos 20 e 42 dias após o plantio (DAP).

As avaliações constaram da taxa de cobertura do solo (\%), determinada com auxílio do software SIARCS 3.0 (Sistema Integrado para Análise de Raízes e Cobertura do Solo), desenvolvido pela Embrapa-Centro Nacional de Pesquisa e Desenvolvimento de Instrumentação Agropecuária. O acompanhamento do crescimento das plantas, até a cobertura total do solo, foi feito por meio de imagens fotográficas aos 8, 21, 34, 49, 64, 83, 104, 125, 149, 178 e 224 DAP. A câmara fotográfica era suspensa por um tripé, de modo que as fotografias fossem tomadas perpendicularmente ao solo, a uma altura de 1,60 m da superfície do terreno. Cada fotografia abrangia uma área de $1 \mathrm{~m}^{2}$, e foi tomada entre 7 h30 e 9 h, a fim de atenuar efeitos adversos de sombra.

Quantificou-se a produção de biomassa de parte aérea, tomando-se por base amostras secadas em estufa de ventilação forçada, a $65^{\circ} \mathrm{C}$. O conteúdo de $\mathrm{N}$ foi determinado após digestão sulfúrica e destilação em Kjeldahl (Bremner \& Mulvaney, 1982); os conteúdos de P e K foram determinados na parte aérea das plantas, após digestão nítrico-perclórica (Bataglia et al., 1983). O P foi determinado em espectrofotômetro baseando-se na formação da cor azul do complexo fosfato-molibdato em meio sulfúrico, na presença de ácido ascórbico como redutor, e o K em espectrofotômetro de absorção atômica, por ocasião do primeiro, segundo, terceiro e quarto cortes rente ao solo, realizados, respectivamente, aos $8,12,22$ e 24 meses após o plantio (MAP).

As análises estatísticas foram realizadas com auxílio do Sistema para Análises Estatísticas e Genéticas (SAEG), versão 5.0 (Euclydes, 1983), e constou da análise de variância, seguida da escolha do modelo que melhor representasse $\mathrm{o}$ ajuste das curvas e aplicação do teste $\mathrm{F}$ nos coeficientes da equação para detectar significância a $5 \%$ e 
a $1 \%$ de probabilidade. Quanto à taxa de cobertura do solo, as curvas foram ajustadas de acordo com a função logística $\mathrm{TC}=\mathrm{A} /\left(1+\mathrm{B}^{-\mathrm{K} \times \mathrm{DAP}}\right)$,

em que TC é a taxa de cobertura do solo (em \%); A é o limite superior da taxa de cobertura do solo; B está relacionado com o tamanho inicial do sistema; Ké a taxa de incremento inerente do sistema. Em relação à produção de matéria seca da parte aérea e acumulação total de N, P e $\mathrm{K}$, os modelos testados foram lineares, quadráticos e cúbicos. A escolha do modelo que representasse a distribuição dos dados foi baseada no comportamento biológico, significância $(\mathrm{p} \leq 0,05)$ e no coeficiente de determinação $\left(\mathrm{R}^{2}\right)$.

\section{Resultados e Discussão}

A interpretação da análise de variância revelou efeito significativo $(\mathrm{p} \leq 0,05)$ da densidade de plantio sobre a taxa de cobertura do solo, produção de matéria seca e acumulação de N, P e K na parte aérea do amendoim forrageiro. Entretanto, não foram detectados efeitos do espaçamento, nem interação entre espaçamento e densidade. Assim, as equações ajustadas aos dados foram baseadas no maior espaçamento testado $(50 \mathrm{~cm})$, porque neste espaçamento utiliza-se um número menor de mudas, amenizando os custos de implantação da cobertura com esta leguminosa.

$\mathrm{O}$ amendoim forrageiro cobriu plenamente o solo aos 224 DAP independentemente das densidades testadas (Figura 1). Vallejos (1993) observou que o estabelecimento do amendoim forrageiro em consórcio com café alcançou $80 \%$ de cobertura do solo aos 210 DAP. Perin (2001) constatou que esta leguminosa cultivada em condições edáficas semelhantes, porém, semeada no período das águas (dezembro), proporcionou plena cobertura do solo aos 110 DAP. As condições climáticas, em especial a precipitação pluvial durante o verão, foram determinantes na velocidade de cobertura do solo.

As maiores diferenças entre as densidades de plantio ocorreram na fase inicial de estabelecimento da cobertura viva. Densidades de 8 e 16 plantas/m linear proporcionaram $50 \%$ de cobertura de terreno, respectivamente, aos 84 e 68 DAP, enquanto nos tratamentos com 2 e 4 plantas/m linear, esse mesmo valor foi alcançado, respectivamente, aos 125 e 103 DAP (Figura 1). Alvarenga et al. (1995) destacam que uma cobertura uniforme de $20 \%$ do terreno é capaz de reduzir as perdas de terra em aproximadamente $50 \%$, quando comparado com solo descoberto.

A cobertura mais rápida nas densidades de $8 \mathrm{e}$ 16 plantas/m linear reduziu a população de ervas espontâneas e, em conseqüência, diminuiu a mão-de-obra para seu controle. Segundo Lanini et al. (1989)e Wiles et al. (1989), a menor ocorrência de plantas espontâneas decorrente do emprego da cobertura viva com leguminosas herbáceas perenes minimiza a competição das ervas no cultivo de hortaliças. Bradshaw \& Siman (1992) e Vallejos (1993) relacionaram custo/ benefício e eficiência no controle da vegetação espontânea e constataram que o amendoim forrageiro apresentou excelente competitividade com as ervas, resultando em menores custos no controle de invasoras, quando comparado com capinas manuais e químicas.

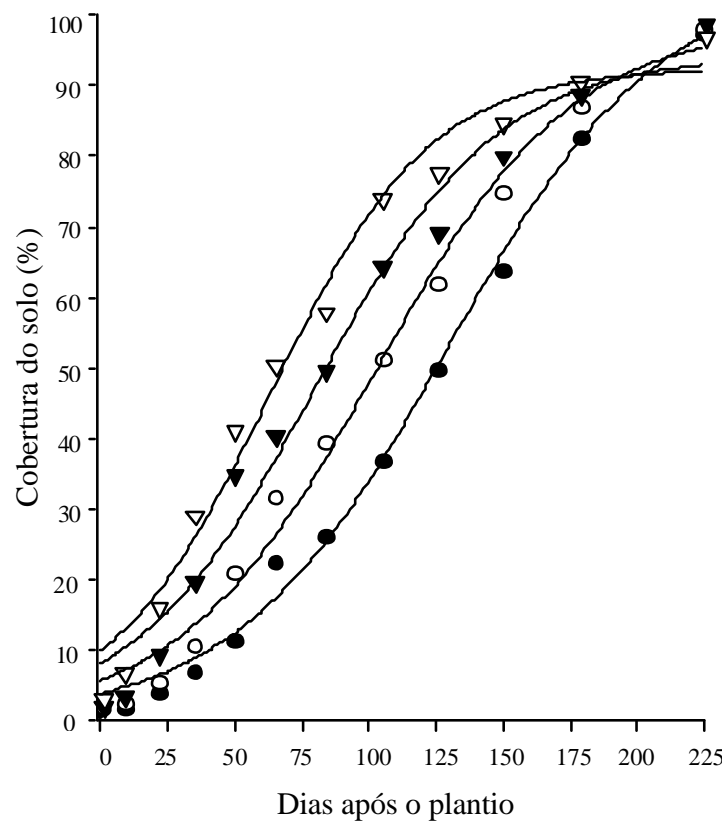

$$
\begin{aligned}
& \mathrm{Y}(\boldsymbol{O})=105,571 /\left(1+26,995^{-0,0255 \times \mathrm{DAP}}\right) ; \mathrm{R}^{2}=0,99 * * \\
& \mathrm{Y}(\mathbf{O})=98,731 /\left(1+16,601^{-0,0275 \times \mathrm{DAP}}\right) ; \mathrm{R}^{2}=0,99 * * \\
& \mathrm{Y}(\boldsymbol{\nabla})=94,189 /\left(1+10,707^{-0,0297 \times \mathrm{DAP}}\right) ; \mathrm{R}^{2}=0,98^{* *} \\
& \mathrm{Y}(\boldsymbol{\nabla})=92.409 /\left(1+8.418^{-0,337 \times \mathrm{DAP}}\right) ; \mathrm{R}^{2}=0.99 * *
\end{aligned}
$$

Figura 1. Taxas de cobertura do solo $(\mathrm{Y})$ por amendoim forrageiro em razão de duas $(\bullet)$, quatro $(0)$, oito $(\boldsymbol{\nabla})$ e dezesseis $(\nabla)$ plantas/m linear e de dias após o plantio (DAP) no espaçamento de $50 \mathrm{~cm}$ entre sulcos. **Significativo a $1 \%$ de probabilidade pelo teste $\mathrm{F}$. 
Por outro lado, se o amendoim compete com as plantas espontâneas, poderá competir também com as culturas de interesse, especialmente quando empregado como cobertura viva em pomares. Perin et al. (2002a) mostraram que a cobertura com esta leguminosa, quando comparada com as coberturas de cudzu tropical e siratro, reduziu o crescimento e a produtividade no segundo ciclo de bananeiras. Embora o amendoim forrageiro proporcione aporte expressivo de $\mathrm{N}$ no pomar de bananeiras (Espindola, 2001), Perin et al. (2002b) observaram que a cobertura viva com esta leguminosa acarretou redução dos níveis de umidade do solo maior do que o detectado com cudzu tropical e siratro. Desta forma, a cobertura com amendoim forrageiro, em condições de déficit hídrico prolongado, pode efetivamente provocar competição por água com a cultura principal.

À medida que aumenta a densidade de plantio, eleva-se linearmente a produção de matéria seca e acumulação de N, P e K na parte aérea das plantas em todos os cortes (Tabela 1). Os modelos lineares indicam que a competição entre plantas não limitou a expressão destes parâmetros, em especial por ocasião do primeiro corte, quando as plantas encontravam-se ainda na fase de estabelecimento. Entretanto, a partir do segundo corte verifica-se decréscimo dos valores do coeficiente dos modelos da regressão para a produção de matéria seca, denotando aumento da competição entre plantas (Tabela 1).

Ao longo do período experimental (dois anos), o amendoim forrageiro acumulou 20 t/ha de matéria seca e 572, 37 e $247 \mathrm{~kg} / \mathrm{ha}$, respectivamente, de $\mathrm{N}$, $\mathrm{P}$ e potássio. Em condições experimentais semelhantes, Espindola (2001) verificou que $91 \%$ do N presente no tecido vegetal do amendoim forrageiro foi obtido pela fixação biológica de $\mathrm{N}_{2}$ (FBN) e quando esta leguminosa encontrava-se consorciada com bananeiras, a FBN alcançou $61 \%$. Assim, pode-se estimar que o aporte de $\mathrm{N}$, via FBN, varia aproximadamente de 350 a $520 \mathrm{~kg} / \mathrm{ha}$. Destaca-se, então, o alto potencial do amendoim forrageiro como cobertura viva, representando uma estratégia para a auto-suficiência em $\mathrm{N}$ na nutrição de fruteiras, por minimizar ou dispensar a utilização da adubação nitrogenada com fertilizantes sintéticos ou outras fontes.
Tabela 1. Equações ajustadas de produção de matéria seca (Y) e acumulação total de N, P e K (Y) na parte aérea de amendoim forrageiro, em razão de $2,4,8$, e 16 plantas/m linear no espaçamento de $50 \mathrm{~cm}$ entre sulcos $(\mathrm{X})$, por ocasião do primeiro $(\bullet)$, segundo $(0)$, terceiro $(\nabla)$ e quarto $(\nabla)$ corte.

\begin{tabular}{|c|c|}
\hline Equação & $\mathrm{R}^{2}$ \\
\hline 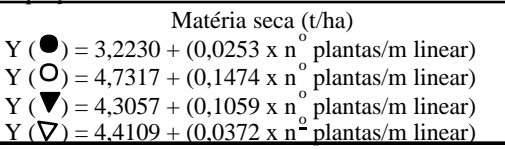 & $\begin{array}{l}0,98^{*} \\
0,89^{*} \\
0,90^{*} \\
0,81^{*} \\
\end{array}$ \\
\hline $\begin{array}{l}\mathrm{N}(\mathrm{kg} / \mathrm{ha}) \\
\mathrm{Y}(\mathbf{O})=100,4078+\left(1,2770 \times \mathrm{n}^{\mathrm{o}} \text { plantas } / \mathrm{m} \text { linear }\right) \\
\mathrm{Y}(\mathbf{O})=127,2417+\left(2,9534 \times \mathrm{n}_{\mathrm{o}} \text { plantas/m linear }\right) \\
\mathrm{Y}(\boldsymbol{\nabla})=140,1478+\left(3,6240 \times \mathrm{n}^{\circ} \text { plantas/m linear }\right) \\
\mathrm{Y}(\boldsymbol{\nabla})=126.9178+\left(0.4200 \times \mathrm{n}^{\mathrm{O}} \text { plantas/m linear }\right)\end{array}$ & $\begin{array}{l}0,89^{*} \\
0,86^{*} \\
0,90^{*} \\
0,85^{*}\end{array}$ \\
\hline $\begin{array}{l}\mathrm{P}(\mathrm{kg} / \mathrm{ha}) \\
\mathrm{Y}(\mathbf{O})=5,9300+\left(0,0730 \times \mathrm{n}^{\circ}{ }^{\circ} \text { plantas } / \mathrm{m} \text { linear }\right) \\
\mathrm{Y}(\mathbf{O})=7,7465+\left(0,2311 \times \mathrm{n}^{\circ} \text { plantas } / \mathrm{m} \text { linear }\right) \\
\mathrm{Y}(\boldsymbol{\nabla})=7,5239+\left(0,3125 \times \mathrm{n}^{\circ}{ }^{\circ} \text { plantas } / \mathrm{m} \text { linear }\right) \\
\mathrm{Y}(\boldsymbol{\nabla})=9,0483+\left(0,0856 \times \mathrm{n}^{\circ} \text { plantas } / \text { m linear }\right)\end{array}$ & $\begin{array}{l}0,99^{*} \\
0,76^{*} \\
0,91^{*} \\
0,72^{\text {ns }} \\
\end{array}$ \\
\hline 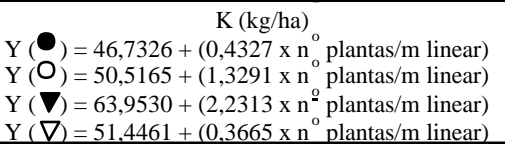 & $\begin{array}{l}0,79^{*} \\
0,78^{*} \\
0,78^{*} \\
0,84^{*}\end{array}$ \\
\hline
\end{tabular}

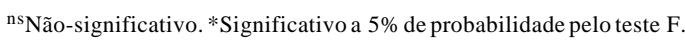

A utilização de 16 plantas/m linear, quando comparada com 8 plantas, resultou em acréscimo de apenas $0,20,1,18,0,85$ e 0,30 t/ha de matéria seca, respectivamente, no primeiro, segundo, terceiro e quarto cortes, no espaçamento de $50 \mathrm{~cm}$ entre sulcos de plantio (Tabela 1). Destaca-se o potencial de rebrota do amendoim forrageiro após os cortes, apresentando elevada produção de matéria seca, mesmo em curtos intervalos de tempo, como observado entre o terceiro e quarto cortes. Este aspecto é também relevante no manejo da cobertura viva, em face da possibilidade de produzir continuamente matéria orgânica de qualidade in situ.

\section{Conclusões}

1. As taxas de cobertura do solo, produção de matéria seca e acumulação de N, P e K na parte aérea de amendoim forrageiro não são afetadas pelos espaçamentos entre sulcos de plantio.

2. As densidades de plantio afetam as taxas de cobertura do solo, produção de matéria seca e acumulação de $\mathrm{N}, \mathrm{P}$ e K na parte aérea de amendoim forrageiro.

3. A densidade de 8 plantas/m linear no espaçamento de $50 \mathrm{~cm}$ entre sulcos de plantio é a 
mais adequada para plena formação da cobertura viva com amendoim forrageiro.

\section{Agradecimentos}

À Embrapa-Centro Nacional de Pesquisa de Agrobiologia, pelo suporte físico e financeiro e aos empregados do campo experimental (Terraço), pela execução das atividades de campo.

\section{Referências}

ALVARENGA, R. C.; COSTA, L. M. da; MOURA FILHO, W.; REGAZZI, A. J. Características de alguns adubos verdes de interesse para a conservação e recuperação de solos. Pesquisa Agropecuária Brasileira, Brasília, v. 30, n. 1, p. 175-185, jan. 1995.

AMABILE, R. F.; FANCELLI, A. L.; CARVALHO, A. M. de. Comportamento de espécies de adubos verdes em diferentes épocas de semeadura e espaçamentos na região dos cerrados. Pesquisa Agropecuária Brasileira, Brasília, v. 35 , n. 1 , p. 47-54, jan. 2000.

BATAGLIA, O. C.; FURLANI, A. M. C.; TEIXEIRA, J. P. F.; FURLANI, P. R.; GALLO, J. R. Métodode análise química de plantas. Campinas: Instituto Agronômico, 1983. p. 1-48. (Boletim Técnico, 78).

BRADSHAW, L.; SIMAN, J. Establecimiento deArachis pintoi como cobertura viva en café. Turrialba: Centro Agronómico Tropical de Investigación y Enseñanza, 1992. $2 \mathrm{p}$.

BREMNER, J. M.; MULVANEY, C. S. Nitrogen total. In: PAGE, A. L.; MILLER, R. A.; KEENEY, D. R. (Ed.). Methods of soil analysis. $2^{\text {nd }}$. Madison: American Society of Agronomy, 1982. p. 595-624. (Agronomy, 9).

DUDA, G. P.; GUERRA, J. G. M.; MONTEIRO, M. T.; DE-POLLI, H.; TEIXEIRA, M. G. Perennial herbaceous legumes as live soil mulches and their effects on $\mathrm{C}, \mathrm{N}$ and $\mathrm{P}$ of the microbial biomass. ScientiaAgricola, Piracicaba, v. 60 , n. 1, p. 139-147, 2003.

ESPINDOLA, J. A. A. Avaliação de leguminosas herbáceas perenes usadas como cobertura viva de solo e seus efeitos sobre a produção da bananeira (Musa spp.). 2001. 144 f. Tese (Doutorado em Agronomia - Ciência do Solo) - Universidade Federal Rural do Rio de Janeiro, Seropédica, 2001.
EUCLYDES, R. F. Manual de utilização do programa SAEG (Sistema para Análises Estatísticas e Genéticas). Viçosa, MG: Imprensa Universitária, 1983. 59 p.

FERNANDES, M. F.; BARRETO, A. C.; EMÍDIO FILHO, J. Fitomassa de adubos verdes e controle de plantas daninhas em diferentes densidades populacionais de leguminosas. Pesquisa Agropecuária Brasileira, Brasília, v. 34, n. 9, p. 1593-1600, set. 1999.

GUERRA, J. G. M.; TEIXEIRA, M. G. Avaliação inicial de algumas leguminosas herbáceas perenes para utilização como cobertura viva permanente de solo. Seropédica: Embrapa-CNPAB, 1997. 7 p (Comunicado Técnico, 16).

HORN, F. L.; SCHUCH, L. O. B.; SILVEIRA, E. P.; ANTUNES, I. F.; VIEIRA, J. C.; MARCHIORI, G.; MEDEIROS, D. F.; SCHWENGBER, J. E. Avaliação de espaçamento e população de plantas de feijão visando à colheita mecanizada direta. Pesquisa Agropecuária Brasileira, Brasília, v. 35, n. 1, p. 41-46, jan. 2000.

KLEINHENZ, V.; SCHNITZLER, W. H.; MIDMORE, D. J. Effects of legume live-mulch on crop performance, soil available nitrogen and crop $\mathrm{N}$ status in intensive tropical vegetable production. Biological Agriculture and Horticulture, Bicester, v. 14, p. 261-278, 1997.

LANINI, W. T.; PITTENGER, D. R.; GRAVES, W. L.; MUÑOZ, F.; AGAMALIAN, H. S. Subclovers as living mulches for managing weeds in vegetables. California Agriculture, Berkeley, v. 43, p. 25-27, 1989.

PERIN, A. Desempenho de leguminosas herbáceas perenes com potencial de utilização para cobertura viva e seus efeitos sobre alguns atributos físicos do solo. 2001. 144 f. Dissertação (Mestrado em Agronomia - Ciência do Solo) - Universidade Federal Rural do Rio de Janeiro, Seropédica, 2001.

PERIN, A.; GUERRA, J. G. M.; TEIXEIRA, M. G.; PEREIRA, M. G.; FONTANA, A. Efeito da cobertura viva com leguminosas herbáceas perenes na agregação de um argissolo. Revista Brasileira de Ciência do Solo, Viçosa (MG), v. 26, n. 3, p. 713-720, jul./set. 2002a.

PERIN, A.; LIMA, E. A. de; ESPINDOLA, J. A. A.; GUERRA, J. G. M.; TEIXEIRA, M. G.; BUSQUET, R. N. $B$. Contribuição da cobertura viva de solo com 
leguminosas herbáceas perenes no 2o ciclo de bananeiras cultivar nanicão. Seropédica: Embrapa-CNPAB, 2002b. 6 p. (Comunicado Técnico, 53).

PERIN, A.; TEIXEIRA, M. G.; GUERRA, J. G. M. Desempenho de algumas leguminosas com potencial para utilização como cobertura viva permanente de solo. Agronomia, Seropédica, v. 34, n. 1/2, p. 38-43, jan./dez. 2000.

PIRES, J. L. F.; COSTA, J. A.; THOMAS, A. L.; MAEHLER, A. R. Efeito de populações e espaçamentos sobre o potencial de rendimento da soja durante a ontogenia. Pesquisa Agropecuária Brasileira, Brasília, v. 35 , n. 1, p. 41-46, jan. 2000.
SARRANTONIO, M. Opportunities and challenges for the inclusion of soil-improving crops in vegetable production systems. HortScience, Alexandria, v. 27, p. 754-758, 1992.

VALLEJOS, C. R. M. Coberturas vivas en el cultivo de café (Coffea arabica), su establecimiento y relación con malezas Meloidogyne exigua. 1993.103 p. Tesis (Maestría en Agronomía) - Centro Agronómico Tropical de Investigación Enseñanza, Turrialba, 1993.

WILES, L. J.; WILLIAM, R. D.; CRABTREE, G. D.; RADOSEVICH, S. R. Analyzing competition between a living mulch and a vegetable crop in an interplanting system. Journal of the American Society for Horticulture Science Journal, Alexandria, v. 114, p. 1029-1034, 1989. 